\title{
Wide propagation of graded signals in nonspiking
}

\section{neurons}

Sung Min Yang, María Eugenia Vilarchao, Lorena Rela and Lidia Szczupak

J Neurophysiol 109:711-720, 2013. First published 14 November 2012;

doi: $10.1152 /$ jn.00934.2012

You might find this additional info useful...

This article cites 42 articles, 27 of which you can access for free at:

http://jn.physiology.org/content/109/3/711.full\#ref-list-1

Updated information and services including high resolution figures, can be found at: http://jn.physiology.org/content/109/3/711.full

Additional material and information about Journal of Neurophysiology can be found at: http://www.the-aps.org/publications/jn

This information is current as of July 24, 2013. 


\title{
Wide propagation of graded signals in nonspiking neurons
}

\author{
Sung Min Yang, ${ }^{1}$ María Eugenia Vilarchao, ${ }^{1}$ Lorena Rela, ${ }^{2}$ and Lidia Szczupak ${ }^{1}$ \\ ${ }^{1}$ Departamento de Fisiología, Biología Molecular y Celular, Facultad de Ciencias Exactas y Naturales Universidad de \\ Buenos Aires (UBA), Instituto de Fisiología, Biología Molecular y Neurociencias UBA-Consejo Nacional de Investigaciones \\ Científicas y Técnicas, Buenos Aires, Argentina; and ${ }^{2}$ Grupo de Neurociencia de Sistemas, Facultad de Medicina, UBA, \\ Buenos Aires, Argentina
}

Submitted 25 October 2012; accepted in final form 7 November 2012

Yang SM, Vilarchao ME, Rela L, Szczupak L. Wide propagation of graded signals in nonspiking neurons. J Neurophysiol 109: 711-720, 2013. First published November 14, 2012; doi:10.1152/jn.00934.2012.— Signal processing in neuritic trees is ruled by the concerted action of passive and active membrane properties that, together, determine the degree of electrical compartmentalization of these trees. We analyzed how active properties modulate spatial propagation of graded signals in a pair of nonspiking (NS) neurons of the leech. NS neurons present a very extensive neuritic tree that mediates the interaction with all the excitatory motoneurons in leech ganglia. NS cells express voltageactivated $\mathrm{Ca}^{2+}$ conductances (VACCs) that, under certain experimental conditions, evoke low-threshold spikes. We studied the distribution of calcium transients in NS neurons loaded with fluorescent calcium probes in response to low-threshold spikes, electrical depolarizing pulses, and synaptic inputs. The three types of stimuli evoked calcium transients of similar characteristics in the four main branches of the neuron. The magnitude of the calcium transients evoked by electrical pulses was a graded function of the change in NS membrane potential and depended on the baseline potential level. The underlying VACCs were partially inactivated at rest and strongly inactivated at $-20 \mathrm{mV}$. Stimulation of mechanosensory pressure cells evoked calcium transients in NS neurons whose amplitude was a linear function of the amplitude of the postsynaptic response. The results evidenced that VACCs aid an efficient propagation of graded signals, turning the vast neuritic tree of NS cells into an electrically compact structure.

low threshold spike; calcium transients; signal propagation

SIGNAL PROCESSING IN DENDRITIC trees has been a subject of intense investigation (Hausser et al. 2000; Magee 2000). The description of a great variety of voltage-activated conductances in dendrites (Reyes 2001; Migliore and Shepherd 2002) has shifted the phenomenon of dendritic processing from one ruled mainly by passive properties to one shaped by the concert of passive and active properties (Segev and London 2000) that, together, determine the degree of electrical compartmentalization of complex neuritic arbors (Hausser and Mel 2003). The image that emerges indicates that, in some cases, voltage-gated conductances act locally at the site of synaptic inputs, boosting incoming graded signals and thus increasing their capacity to reach distant sites; and in other cases, voltage-gated conductances mediate the actual propagation of signals along dendrites. Because the chance of any incoming signal to influence the output of a neuron depends on the efficiency of its spatial spread, voltage-gated conductances play an important role in the input/output function of any neuron.

Address for reprint requests and other correspondence: L. Szczupak; Ciudad Universitaria, Pabellón II, piso 2. 1428 CABA, Argentina (e-mail: szczupak@retina.ar).
Nonspiking neurons are a category of cells that do not fire all-or-none action potentials, and their output is a graded function of the membrane potential (Burrows 1979; Wadepuhl 1989; Thoreson et al. 2004). Although nonspiking neurons do not fire canonical spikes, they do express a variety of voltagegated conductances that influence their input-output function (Laurent 1990; Protti et al. 2000; Zenisek et al. 2001; Husch et al. 2009). However, how active properties modulate spatial propagation and graded signaling in nonspiking neurons is still an open question.

The NS (for nonspiking) neurons of the leech constitute an interesting example of this type of neurons. They are present as pairs in each midbody ganglion and are linked to virtually every excitatory motoneuron in the leech ganglion by rectifying junctions that allow graded regulation of the membrane potential of the motoneurons. On the other hand, the excitatory motoneurons exert a net inhibitory effect on NS neurons through chemically mediated synapses (Wadepuhl 1989; Rela and Szczupak 2003, 2007; Rodriguez et al. 2009). These network interactions suggest that NS neurons play a key role in modulating motor output in the leech. Recently, we have shown that NS neurons regulate the crawling motor pattern, affecting both the level of motoneuron activity as well as the period of the rhythmic motor output (Rodriguez et al. 2012).

NS neurons present a very extensive neuritic tree (Fig. 1), with branches leaving to the periphery through ipsilateral and contralateral root nerves and to adjacent ganglia through anterior and posterior connective nerves (Wadepuhl 1989). Propagation of electrophysiological signals in such an extensive neuritic tree by means of purely passive spread could imply that the neuron operates as a multicompartmentalized structure. However, NS neurons express voltage-activated $\mathrm{Ca}^{2+}$ conductances (VACCs) that, under certain experimental conditions, give rise to low-threshold spikes (Rela et al. 2009). To investigate the role of VACCs in NS signal processing we studied the distribution of calcium transients throughout the dendritic tree of these cells. The results indicate that NS membrane holds a widespread distribution of VACCs that mediates an efficient propagation of graded signals throughout the extensive NS neuritic tree, turning it into an electrically compact structure.

\section{MATERIALS AND METHODS}

Biological preparation. Hirudo sp, weighing 2-5 g, were obtained from a commercial supplier (Leeches, Westbury, NY) and maintained at $15^{\circ} \mathrm{C}$ in artificial pond water. The animals were not fed for at least 1 mo before dissection. The leech nervous system is composed of 21 midbody ganglia, aligned between a head and a tail brain. Each midbody ganglion innervates one body segment and contains all the corresponding sensory and motor neurons (Muller et al. 1981). The 


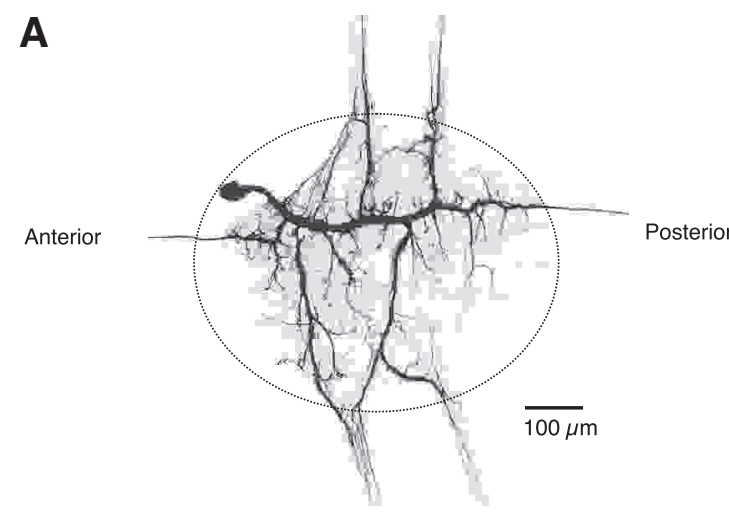

B

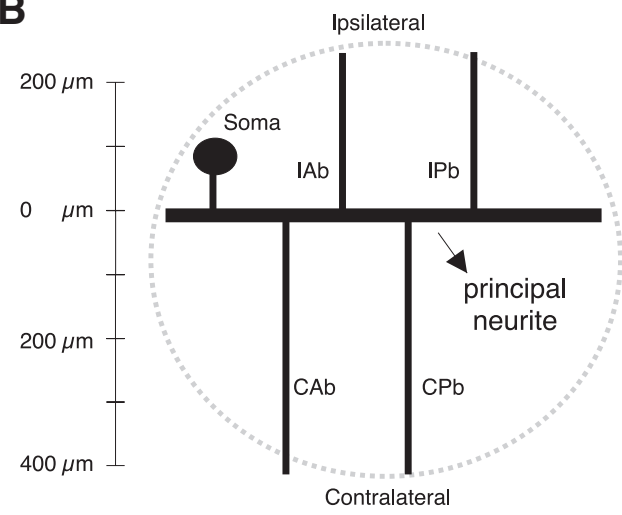

Fig. 1. Nonspiking (NS) morphology. A: projected confocal z-scan of a midbody ganglion where one NS neuron was filled with rhodamine dextran (3 $\mathrm{kDa}$ ). Anterior and posterior ends of the ganglion are indicated. Image is formed by the superposition of 15 focal planes taken at $1-\mu \mathrm{m}$ intervals. Dotted line shows the approximate contour of the ganglion. $B$ : general scheme of the NS neuron composed of a soma that gives rise to a principal neurite that runs parallel to the anterior-posterior axis. Four main branches emerge from this principal neurite: two branches that exit through the anterior and posterior ipsilateral roots (IAb and IPb, respectively) and two branches that exit through the anterior and posterior contralateral roots $(\mathrm{CAb}$ and $\mathrm{CPb}$, respectively). The position along these branches is indicated as the distance from the principal neurite in the scale at left.

ganglia are interconnected by a pair of connective nerves and an unpaired nerve; sensory and motor neurons reach the periphery through a pair of anterior and posterior nerve roots.

Individual midbody ganglia were dissected out of the animal and pinned to Sylgard (Dow Corning) in a recording chamber held at room temperature. The sheath covering the ganglion was dissected away, leaving the neuronal cell bodies exposed to the external solution.

Solutions. The ganglia were bathed in standard saline solution with the following composition (in $\mathrm{mM}$ ): $115 \mathrm{NaCl}, 4 \mathrm{KCl}, 1.8 \mathrm{CaCl}_{2}, 1$ $\mathrm{MgCl}_{2}$, and 5.4 Tris base $\mathrm{pH} \mathrm{7.4.} \mathrm{Where} \mathrm{stated,} \mathrm{we} \mathrm{used} \mathrm{a} \mathrm{solution}$ with a high $\mathrm{Mg}^{2+}$-to- $\mathrm{Ca}^{2+}$ ratio $\left(20 \mathrm{mM} \mathrm{MgCl} 2\right.$ and $\left.1 \mathrm{mM} \mathrm{CaCl}_{2}\right)$ that blocks calcium channels in the leech (Baylor and Nicholls 1969). In this solution, the osmolarity was kept constant by reducing the $\mathrm{NaCl}$ concentration.

Electrophysiological recordings. Neuronal activity was recorded using intracellular glass microelectrodes connected to an Axoclamp 2B amplifier (Axon Instruments, Union City, CA) operating in the current-clamp configuration or, when stated, in discontinuous current clamp (DCC). When the current-clamp mode was used the electrodes were bridge-balanced. Microelectrodes were pulled from borosilicate capillary tubing (FHC, Brunswick, ME) and filled with $3 \mathrm{M}$ potassium acetate solution. Electrodes with resistance of 20-50 M $\Omega$ were selected. The recordings were digitized using a Digidata 1320 interface and acquired using Clampex protocols (pClamp 9.2; Axon
Instruments) at sampling frequencies of 5-10 kHz. The NS and the mechanosensory $(\mathrm{P})$ neurons were identified by their location, size, and electrophysiological properties (Muller et al. 1981; Wadepuhl 1989). In each ganglion, there is one bilateral pair of medial P cells $(\mathrm{Pm})$ and one bilateral pair of lateral $\mathrm{P}$ cells $(\mathrm{Pl})$ that innervate the dorsal and ventral portions of the skin, respectively. A P cell is denoted as ipsilateral to NS when the somata of both neurons are located in the same right or left hemiganglion. Where stated, the membrane potential of the neurons was shifted to different values injecting a DCC through the recording electrode. To activate the P-NS synapse, $\mathrm{P}$ cells were excited by the application of 1-s trains of 5-ms current pulses (2-4 nA), where each pulse evoked a single spike. The pulse frequency was varied within physiological values $(4-25 \mathrm{~Hz})$. The input resistance of NS neurons was measured by applying $300-\mathrm{ms}$ current pulses of $-0.5 \mathrm{nA}$.

$\mathrm{Ca}^{2+}$ imaging. To analyze the changes in intracellular calcium concentration, evoked by the different electrophysiological protocols, NS neurons were filled with the calcium sensitive fluorescent probe Oregon Green 488 BAPTA-1 (OG-1, $K_{\mathrm{d}}=170 \mathrm{nM}$ ) in the form of membrane impermeable potassium salt (Invitrogen, Molecular Probes). The indicator was diluted in $100 \mathrm{mM}$ potassium acetate solution to a $5-\mathrm{mM}$ concentration and loaded by iontophoresis through an intracellular electrode into the soma. For this purpose, we used a protocol consisting of a $-6 \mathrm{nA}$ pulse $(500 \mathrm{~ms})$ preceded by a $0.2 \mathrm{nA}$ $(100 \mathrm{~ms})$ pulse; this sequence was repeated for $15 \mathrm{~min}$ at $1 \mathrm{~Hz}$. After loading the indicator, it was allowed to diffuse at room temperature for 90 min, changing the saline solution bathing the ganglion every 30 min.

Images were acquired in a FV1000 confocal system (Olympus, Nagano, Japan), using a $\times 20$ water immersion objective (numerical aperture 0.5). Excitation was performed using an Argon laser (488 $\mathrm{nm})$. Excitation and emission wavelengths were separated with a dichroic mirror (DM405/488), and emitted light was filtered through a BA505IF filter. Frames formed by $256 \times 256$ pixels, at a resolution of $2.5 \times 2.5 \mu \mathrm{m}^{2}$, were acquired at $2.2 \mathrm{~Hz}$. Using a pinhole aperture of $300 \mu \mathrm{m}$, we chose the focal plane exhibiting the most complete view of the NS structure and adjusted the photomultiplier (PMT) voltage to get most of the neuron pixels within $7-60 \%$ the dynamic range of the PMT. Optical and electrophysiological data acquisition was synchronized.

In many cases, the fluorescent emission from segments of the NS neuritic tree was occluded by somata of other neurons that covered them. Mechanical removal of somata was tried, improving visualization. However, in many cases, this rendered physiologically damaged NS neurons and therefore this alternative was not further pursued.

Data analysis. The electrophysiological data were analyzed using Clampfit protocols (pClamp, Axon Instruments) and custom-made software. The images were analyzed with custom made software. The first step in image processing was a Gaussian smoothing, using a $3 \times 3$ kernel and $\sigma=0.849$. The background level was estimated by measuring the fluorescence in squares formed by $3 \times 3$ pixels (superpixels) randomly chosen out of the ganglion. Changes in fluorescence due to bleaching were negligible in our protocols.

The pixels within the neurites were recognized by direct inspection. Data were collected from superpixels, whose fluorescence signal was the average of the nine pixels and its location was that of the central pixel. To measure the basal fluorescence $\left(\mathrm{F}_{0}\right)$, we subtracted the background fluorescence of the frame and calculated the average $F_{0}$ in 10 frames previous to the stimulus. The change in fluorescence evoked by the different protocols was calculated as $\Delta \mathrm{F} / \mathrm{F}=[\mathrm{F}(\mathrm{t})-$ $\left.\mathrm{F}_{\mathrm{o}}\right] / \mathrm{F}_{\mathrm{O}} * 100 \%$.

We stimulated the NS cells in three ways: 1) hyperpolarizing pulses injected into NS that evoked a low-threshold spike; 2) depolarizing electrical pulses into NS; and 3) synaptic stimuli evoked by a train of pulses injected in the mechanosensory $\mathrm{P}$ cells. In the first case, $t=0$ was established at the end of the pulse; for depolarizing pulses, $t=0$ was set at the onset of the pulse injected in NS; and for synaptically 
evoked responses, $t=0$ was at the onset of the train of pulses injected in the $\mathrm{P}$ cell.

The amplitude of the optical signal was measured as the average $\Delta \mathrm{F} / \mathrm{F}$ during the first $5 \mathrm{~s}$. The time to peak ( $\mathrm{Tp}$ ) and width were measured in a low pass filtered $(0.25 \mathrm{~Hz})$ version of the optical signal. The width was measured at $50 \%$ the filtered $\Delta \mathrm{F} / \mathrm{F}$ peak value.

The NS neurites were divided in regions of interest (ROIs) of 7.5 $\mu \mathrm{m} \times 40 \mu \mathrm{m}$. For a ROI to be computed, $>40 \%$ of its superpixels had to contain at least six (out of 9) pixels that fulfill two conditions: $F_{0}$ had to be at least three times larger than the background fluorescence and $<73 \%$ of the upper limit of the PMT. The soma was ignored because the conditions that were suitable to measure $\Delta F / F$ in the neurites left the soma at saturated values.

The synaptic responses of NS to P cell stimulation were quantified by measuring the area under the curve during $5 \mathrm{~s}$ following the onset of the stimulus, divided by the integration period.

To cope with the variability between different NS neurons and allow certain spatial comparison of the calcium transients, the $\Delta \mathrm{F} / \mathrm{F}$ signals evoked by depolarizing pulses and by synaptic stimulation were expressed relative to those evoked by the low-threshold spike in each ROI (relative $\Delta \mathrm{F}$ amplitude). The results are expressed as average value $\pm \mathrm{SE}$, unless otherwise stated.

\section{RESULTS}

NS structure. Each midbody ganglion presents a single pair of NS neurons whose somata are located at the anterior end of its ventral aspect. The two cells are electrically and dye coupled (Wadepuhl 1989; Rela and Szczupak 2003). Figure $1 A$ shows a confocal image of a ganglion in which the morphology of one NS neuron is revealed by the injection of a fluorescent dye (rhodamine dextrane). From the soma, a single neurite emerges and traverses the ganglion parallel to the anteriorposterior axis and exits through the posterior ipsilateral connective nerve. From this principal neurite, several branches emerge. Among them, one extends through the anterior ipsilateral connective nerve, and other two prominent pairs of main branches emerge and cross the ganglion parallel to the leftright axis, exiting through the anterior and posterior ipsilateral and contralateral roots. In the present study we attempt a description of the distribution of calcium transient in these neurons, and therefore, for the sake of simplicity we adopted the structural diagram shown in Fig. $1 B$. The optical measurements focused on the four main branches, while the changes in NS membrane potential $\left(V m_{\mathrm{NS}}\right)$ were recorded intracellularly at the soma.

To analyze the contribution of VACCs to signal propagation in NS neurons the cells were stimulated in three different ways: 1) activating low-threshold spikes, 2) injecting depolarizing current pulses of increasing amplitude in their soma, and 3) through synaptic stimulation. The low-threshold-rebound spikes are $\mathrm{Ca}^{2+}$ spikes, and therefore, they were the obvious initial step to investigate the distribution of calcium transients throughout the NS neuritic tree. While electrically induced depolarizations are initiated by stimuli applied at the soma, the synaptic responses are originated in the neuropil, and therefore these two stimuli tested the spatial profile of calcium transients originated at different sites. In addition, the electrical and synaptically induced depolarizations were used to examine whether the calcium transients are graded or all-or-none phenomena and to describe their dependence on the magnitude of changes in $V m_{\mathrm{NS}}$.
Low-threshold-rebound spikes evoked calcium transients in NS neurons. NS neurons fire low-threshold spikes through the activation of VACCs (Rela et al. 2009). These spikes can be elicited on the rebound from a deep hyperpolarization or in the rising phase of a fast depolarization. When elicited by hyperpolarizing pulses, the dynamics of the spike is independent from the dynamics of the stimulus since the spike develops at the end of the current pulse. Here we will refer to this phenomenon as the low-threshold-rebound spike.

In a first instance we analyzed whether the low-thresholdrebound spikes evoke discernible changes in the intracellular $\mathrm{Ca}^{2+}$ concentration in NS neurons. To this end we loaded NS neurons with a $\mathrm{Ca}^{2+}$ indicator, Oregon Green 488 BAPTA-1. The fluorescent dye readily diffused throughout the neuritic tree (Fig. 2Ai). From a resting potential of around $-40 \mathrm{mV}$, the injection of a $-8 \mathrm{nA}$ pulse ( $2 \mathrm{~s})$ elicited a low-thresholdrebound spike (Fig. $2 B$, bottom) that evoked strong $\Delta \mathrm{F} / \mathrm{F}$ signals (Fig. 2B, top). The optical signals were observed throughout the entire neuritic tree revealed by the indicator baseline fluorescence (Fig. 2Aii).
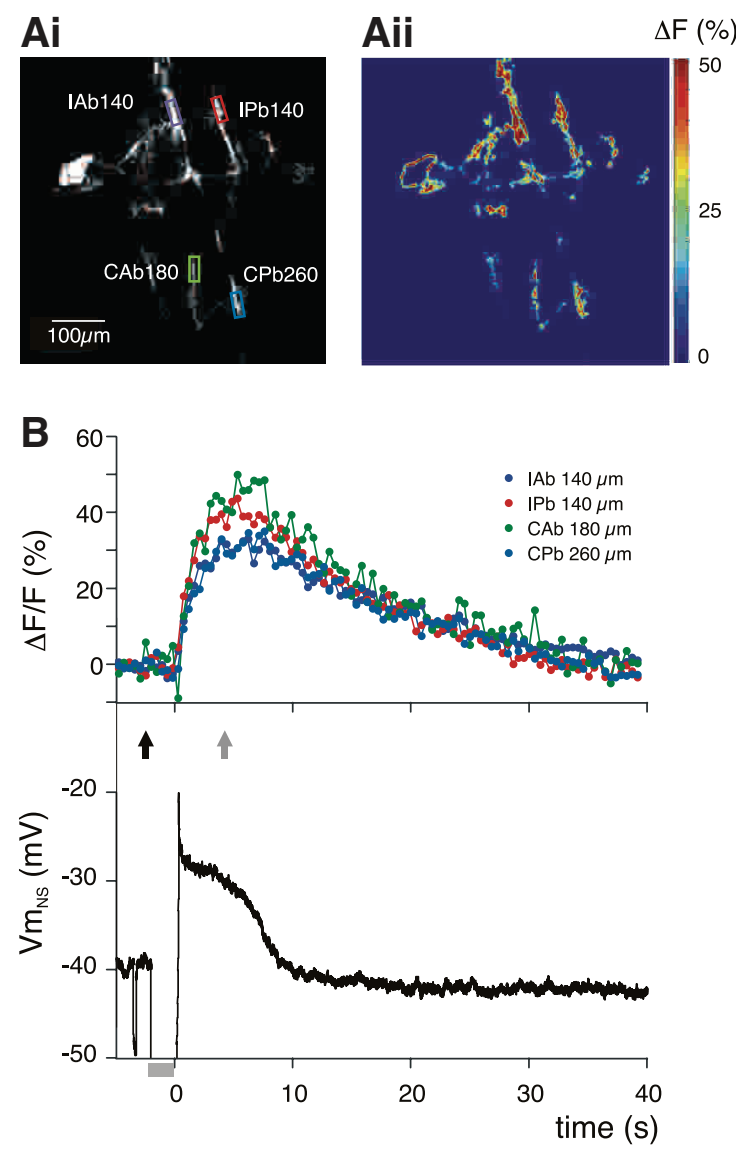

Fig. 2. Low-threshold-rebound spikes evoke calcium transients in NS neurons. $A i$ : confocal plane of a midbody ganglion where one NS neuron was filled with OG-1. Neuron was at its resting NS membrane potential $\left(V m_{\mathrm{NS}}\right)$. Four regions of interest are enclosed in color line boxes. Aii: same confocal plane $3.8 \mathrm{~s}$ after the end of a -8 -nA pulse $(2 \mathrm{~s})$ injected in the NS soma. Color indicates the fluorescence change according to the scale on the right. $B$, bottom: electrophysiological somatic recording of the NS neuron shown in $A$ subjected to a -8 -nA pulse. Gray rectangle underneath indicates the pulse timing. $B$, top: $\Delta \mathrm{F} / \mathrm{F}$ signal evoked by the electrical pulse in the four regions of interest indicated in $A$. Black arrow indicates the time corresponding to $A i$, and gray arrow indicates the time corresponding to Aii. 
The stimulus chosen evokes a fully developed low-threshold-rebound spike in NS neurons (Rela et al. 2009). To verify that the optical signals were due to this regenerative phenomenon and were not an artifact produced by the stimulation protocol per se, we repeated the experiments in two conditions that are known to prevent the development of low-thresholdrebound spikes: 1) in the presence of a high $\mathrm{Mg}^{2+}$ concentration and 2) when the cell was hyperpolarized (to a $V m_{\mathrm{NS}}$ around $-70 \mathrm{mV}$ ) below the activation threshold of the underlying VACCs. In both conditions, the amplitude of the $\Delta \mathrm{F} / \mathrm{F}$ signal was nil: the $\Delta \mathrm{F} / \mathrm{F}$ amplitude was $0.6 \pm 0.2 \%(n=133$ ROIs in 8 ganglia) and $-1.7 \pm 0.3 \%(n=58$ ROIs in 10 ganglia), respectively. The effects of these two experimental manipulations on the low-threshold-rebound spike and on the $\Delta \mathrm{F} / \mathrm{F}$ signal were reversible upon restoration of control conditions (not shown).

To characterize the spatial distribution of the calcium transients in the NS neuritic tree, we measured the amplitude of $\Delta \mathrm{F} / \mathrm{F}$, its time to peak (Tp) and its width as a function of the distance from the principal neurite in each main branch. The results presented in Fig. 3 show that the calcium transients displayed similar amplitude and dynamic profiles in the four

A

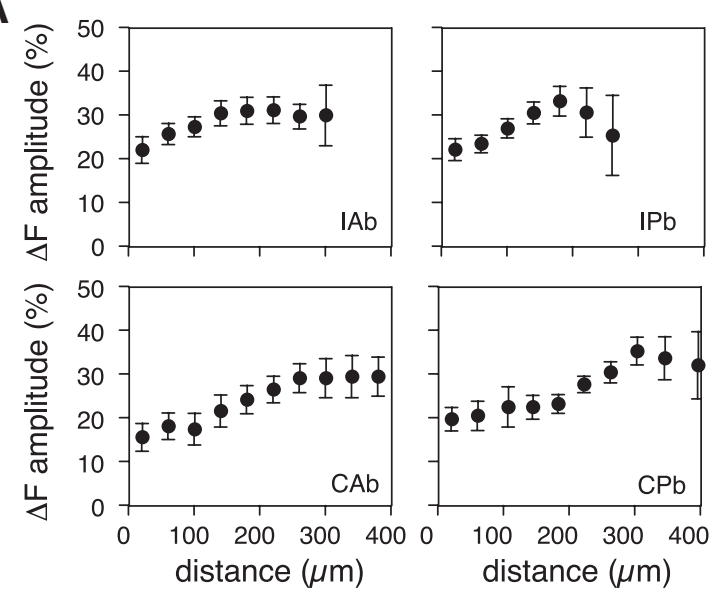

B
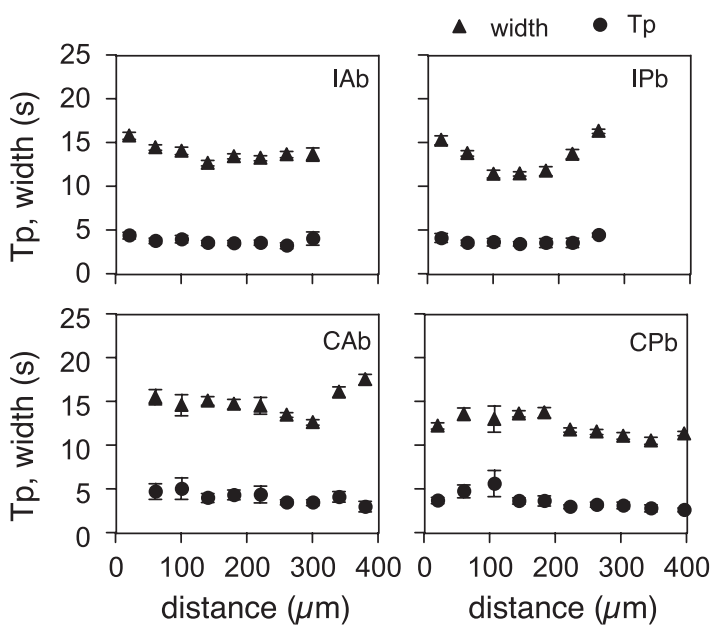

Fig. 3. Low-threshold-rebound spikes evoke calcium transients of similar characteristics along NS branches. Graphs show the mean amplitude $(A)$ and the time to peak (Tp) and the width $(B)$ of the $\Delta \mathrm{F} / \mathrm{F}$ signals in the four main branches as a function of the distance from the principal neurite $(n=73$ ganglia). The identity of each branch is indicated at the right bottom or top corner of each graph. main branches. The amplitude increased with distance from the principal branch, but this trend could be explained on technical grounds: compared with proximal sites, the distal neurites tend to exhibit an increase in the surface to volume ratio and smaller probe concentration. These two factors could explain the increase in the amplitude of the $\Delta \mathrm{F} / \mathrm{F}$ signal (Lev-ram et al. 1992; Neher and Augustine 1992). Therefore, we interpret that the calcium transients were relatively similar throughout each branch, with an average ( \pm SD) amplitude of $25 \%$ (26.72 \pm 4.97), a time to peak of $4 \mathrm{~s}(3.95 \pm 0.85)$, and a width of $13 \mathrm{~s}$ $(13.85 \pm 2.15)$.

Responses of NS to depolarizing pulses depended on baseline level. The above series of experiments shows that lowthreshold-rebound spikes elicited calcium transients throughout the NS neuritic tree. Is direct depolarization of NS neurons able to activate the same widespread phenomenon? What is the relationship between the calcium transients and $V m_{\mathrm{NS}}$ ? To address these questions we recorded the optical signal in response to current injected in the soma. However, first, we needed to undertake a characterization of the electrophysiological responses of NS neurons to this type of stimuli.

NS neurons were subjected to a series of 200-ms depolarizing pulses of increasing amplitude ( 0.5 to $3.0 \mathrm{nA}$ ). Since at rest (around $-40 \mathrm{mV}$ ) NS neurons are above the spike threshold (around $-55 \mathrm{mV}$; Rela et al. 2009), this protocol was tested with $V m_{\mathrm{NS}}$ baseline in three conditions: 1) at rest, 2) at a potential below this threshold (approximately $-60 \mathrm{mV}$ ), and 3) at a potential well above resting potential (approximately -20 $\mathrm{mV}$ ). The experiments were performed in DCC mode to get a more reliable $V m_{\mathrm{NS}}$ measure. Figure $4 A$ shows a representative example of the results: the series of pulses gradually depolarized the NS neuron in the three conditions, but the profile of the responses varied drastically among them. With $V m_{\mathrm{NS}}$ at rest (Fig. 4A, middle) the cell developed, beyond a certain threshold, graded spike-like events in the course of the rising phase of the response; these events were more pronounced when $V m_{\mathrm{NS}}$ baseline was set at $-60 \mathrm{mV}$ (Fig. 4A, left); and the regenerative responses were not discernible at any stimulus intensity when the neuron was set at $-20 \mathrm{mV}$ (Fig. 4A, right). Figure $4 B i$ summarizes the results obtained in this series of experiments in a graph that shows the maximum $V m_{\mathrm{NS}}$ achieved (the highest value achieved in each trace) as a function of the injected current. This graph shows that the magnitude of $V m_{\mathrm{NS}}$ change highly depended on the baseline level. To quantify this observation we plotted the maximum amplitude of the responses (from baseline to maximum value) as a function of the current intensity (Fig. 4Bii). These data indicate that at $-40 \mathrm{mV}$ successively increasing pulses produced moderate increments in the amplitude of the responses, approaching a plateau magnitude of $\sim 30 \mathrm{mV}$; at $-60 \mathrm{mV}$ the responses increased at a steeper rate and the $V m_{\mathrm{NS}}$ change approached a plateau magnitude of $\sim 40 \mathrm{mV}$; and at $-20 \mathrm{mV}$ the $V m_{\mathrm{NS}}$ change was a fairly linear function of the current intensity $(R=0.998 ; P<0.0001)$, within the range used in these experiments.

The previously described electrophysiological behavior cannot be explained on the basis of the input resistance $\left(R_{\mathrm{i}}\right)$ measured in these three conditions; at -20 and $-40 \mathrm{mV} R_{\mathrm{i}}$ was $\sim 20 \mathrm{M} \Omega(20 \pm 2$ and $24 \pm 3 \mathrm{M} \Omega$, respectively), while at $-60 \mathrm{mV} R_{\mathrm{i}}$ was $\sim 10 \mathrm{M} \Omega(10 \pm 1 \mathrm{M} \Omega)$. Thus NS neurons showed a higher responsiveness at $-60 \mathrm{mV}$ in spite of the fact 
A
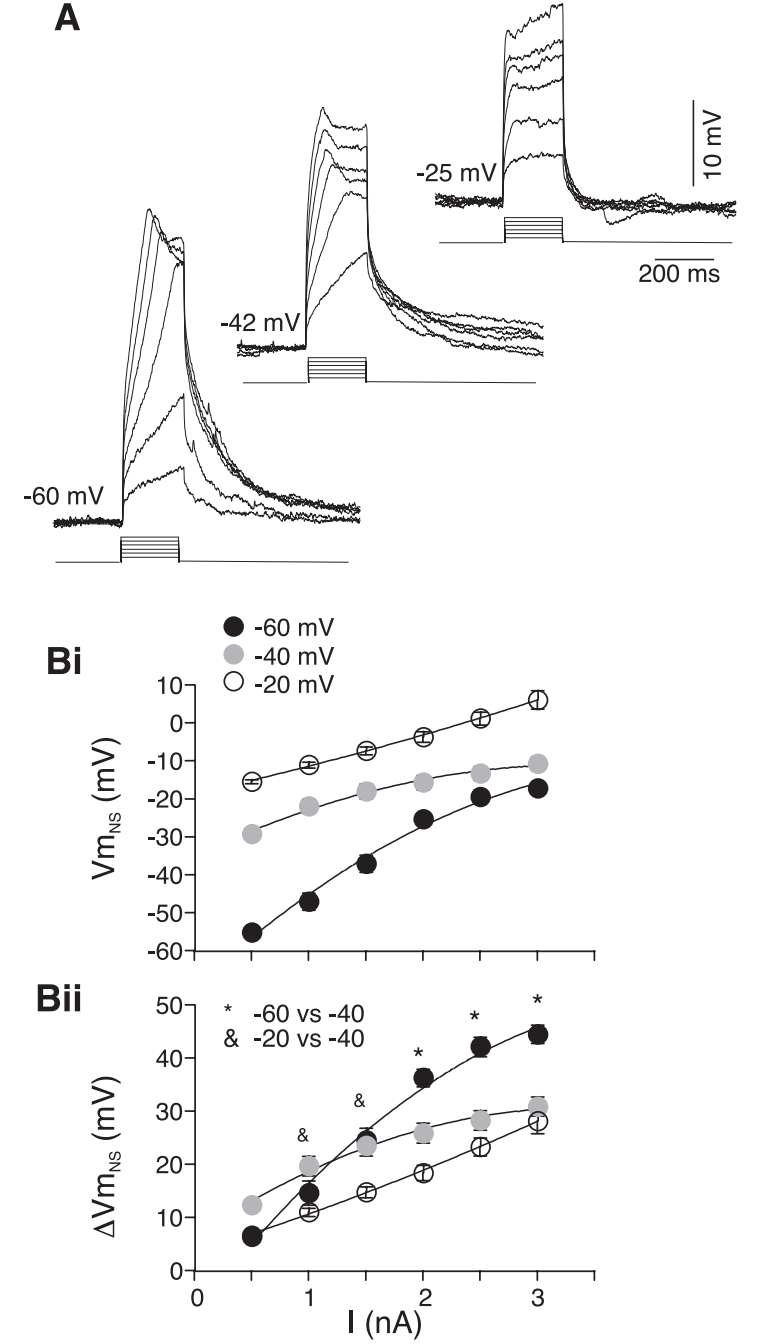

Fig. 4. Voltage dependence of NS responses to depolarizing pulses. $A$ : representative electrophysiological responses of an NS neuron to a series of 200-ms pulses (0.5-3.0 nA at 0.5-nA intervals) injected in the soma when the baseline $V m_{\mathrm{NS}}$ was at rest $(-40 \mathrm{mV})$ or set at approximately -60 and -20 $\mathrm{mV}$. Baseline $V m_{\mathrm{NS}}$ is indicated at left of the traces and the line steps underneath indicate the timing of the current pulses. Experiments were performed in discontinuous current-clamp (DCC) mode. Bi: average maximum $V m_{\mathrm{NS}}$ as a function of the magnitude of the current pulse for the three baseline values ( $n=7$ ganglia). Bii: mean maximum $V m_{\mathrm{NS}}$ change as a function of the magnitude of the current pulse. For clarity, in $B$, the data points were linked, fitting them with a polynomial function of second order. Symbols on top of the data points indicate $P<0.001$, for responses obtained at $-60 \mathrm{mV}\left(^{*}\right)$ and -20 $\mathrm{mV}(\&)$, compared with those obtained at $-40 \mathrm{mV}$, using a two-way ANOVA with repeated measures and Tukey's post hoc tests.

that at this $V m_{\mathrm{NS}}$ the cell exhibited a lower Ri than at -40 and $-20 \mathrm{mV}$.

These results strongly indicate that at $-20 \mathrm{mV}$ the NS cell showed an ohmic behavior, while in the $-60-$ to $-40-\mathrm{mV}$ range the dynamics and the magnitude of the responses were shaped by voltage-gated conductances. At $-40 \mathrm{mV}$, this voltage-gated conductances were partially inactivated and this curtailed the responsiveness of the neuron while at $-20 \mathrm{mV}$ this conductance was fully inactivated.

Depolarizing pulses evoked calcium transients in NS neurons. Using the current pulse protocol described above, we investigated the relationship between the magnitude of the calcium transients and $V m_{\mathrm{NS}}$. Figure $5 \mathrm{~A}$ shows a representative exam- ple of optical measurements made in an NS cell whose baseline was set at $-60 \mathrm{mV}$; application of 200-ms pulses of increasing intensity evoked $\Delta \mathrm{F} / \mathrm{F}$ signals of increasing amplitude.

To describe the spatial distribution of the calcium transients evoked by depolarizing pulses we plotted the amplitude measured at distal vs. proximal sites on the same branch (Fig. 5B). Most of the points fall close to a ratio of one. The mean distal/proximal ratio was $1.12 \pm 0.05$. These results indicate that the calcium transients evoked by depolarizing pulses injected in the NS soma presented a relatively uniform amplitude along any single branch.

Figure $5 C$ displays the relationship between the relative $\Delta \mathrm{F} / \mathrm{F}$ amplitude and the intensity of the injected current for experiments performed at a $-60 \mathrm{mV}$ baseline in each main branch. The four main branches show a highly similar profile: the $\Delta \mathrm{F} / \mathrm{F}$ amplitude increased gradually with current intensity up to a plateau value that was achieved at $\sim 2 \mathrm{nA}$. At this plateau, the $\Delta \mathrm{F} / \mathrm{F}$ signal was around half that evoked by low-threshold-rebound spikes.

Taken together, these results indicate that depolarizing current pulses injected in the soma evoked similar calcium transients throughout the four main branches.

The calcium transients were a graded function of the intensity of the depolarizing pulses. The series of depolarizing pulses was repeated in the same preparations at a $-20 \mathrm{mV}$ baseline and in a different set of preparations at $-40 \mathrm{mV}$. As for the experiments performed at $-60 \mathrm{mV}$, the four branches showed the same profile; therefore, the data for the four branches were combined in a single graph. Figure $6 \mathrm{~A}$ shows that the amplitude of the $\Delta \mathrm{F} / \mathrm{F}$ signals increased as a function of the current intensity, but these responses were strongly influenced by the $V m_{\mathrm{NS}}$ baseline level.

Because the baseline level conditioned the magnitude of the electrophysiological responses of the NS neurons, it was important to relate the amplitude of the $\Delta \mathrm{F} / \mathrm{F}$ signals to the $V m_{\mathrm{NS}}$ achieved at each current pulse (Fig. 6Bi). Given that the imaging experiments were performed in bridge mode and they may carry some error in the voltage measures, the values of $V m_{\mathrm{NS}}$ were taken from the experiments performed in DCC mode (Fig. 4Bi) in which each current intensity is associated with a $V m_{\mathrm{NS}}$ value. Figure $6 B i$ shows that, compared with the $-40-\mathrm{mV}$ baseline, at $-60 \mathrm{mV}$ the NS neuron displayed a larger dynamic range in electrophysiological and calcium signaling terms, while setting the cell at $-20 \mathrm{mV}$ mostly impaired its ability to display calcium transients, compared with the resting condition.

Figure 6Bii displays the relationship between the amplitude of the $\Delta \mathrm{F} / \mathrm{F}$ signals and the amplitude of $V m_{\mathrm{NS}}$ change (taken from Fig. 4Bii) at each baseline level, and Fig. 6Biii displays the same data binned at $10-\mathrm{mV}$ intervals. The constraint imposed by the $-40-\mathrm{mV}$ condition on the calcium signals could be due, in part, to the limits in the electrophysiological responsiveness observed in this condition: at a $-60 \mathrm{mV}$ baseline NS achieved larger voltage excursions than at $-40 \mathrm{mV}$. Yet, Fig. 6Biii shows that for intermediate changes in membrane potential (by $\sim 20 \mathrm{mV}$ ) the $-60-\mathrm{mV}$ condition gave place to statistically larger $\Delta \mathrm{F} / \mathrm{F}$ signals than the $-40-\mathrm{mV}$ condition. At $-20 \mathrm{mV}$, the $\Delta \mathrm{F} / \mathrm{F}$ signals were significantly smaller.

Taken together, these results show that the magnitude of the calcium transients was a graded function of $V m_{\mathrm{NS}}$, and de- 
pended on the baseline $V m_{\mathrm{NS}}$ level. We interpret that shifting $V m_{\mathrm{NS}}$ baseline from rest to $-60 \mathrm{mV}$ deinactivated the voltagegated $\mathrm{Ca}^{2+}$ conductance responsible for the electrical and $\Delta \mathrm{F} / \mathrm{F}$ responsiveness of the cell and potentiated the calcium influx, while shifting $V m_{\mathrm{NS}}$ baseline to $-20 \mathrm{mV}$ largely inactivated this $\mathrm{Ca}^{2+}$ conductance.

Calcium transients were abolished by high $\mathrm{Mg}^{2+}$. To evaluate whether the calcium transients depend on $\mathrm{Ca}^{2+}$ inflow from extracellular space, experiments were performed in the presence of high $\mathrm{Mg}^{2+}$.

To this end we compared the responses, at a $-60 \mathrm{mV}$ baseline, to 200-ms depolarizing pulses in normal saline and in high $\mathrm{Mg}^{2+}$ (Fig. 7A). The $\Delta \mathrm{F} / \mathrm{F}$ signals were reversibly abolished when normal saline was replaced by high $\mathrm{Mg}^{2+}$ saline ( $P<0.001$, Wilcoxon rank sign test for paired data), strongly

A

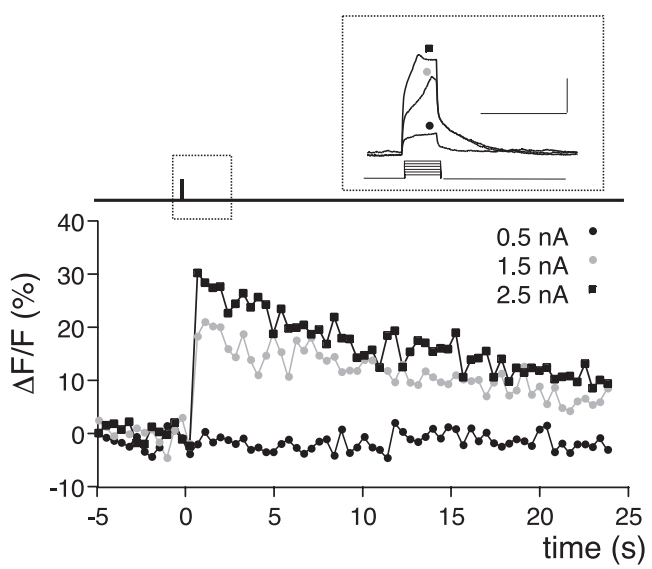

B

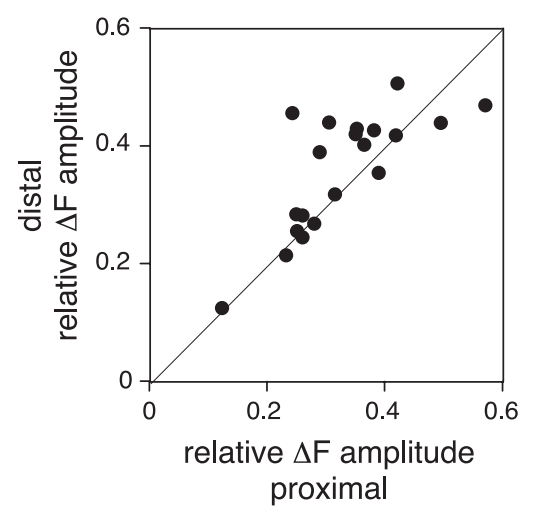

C
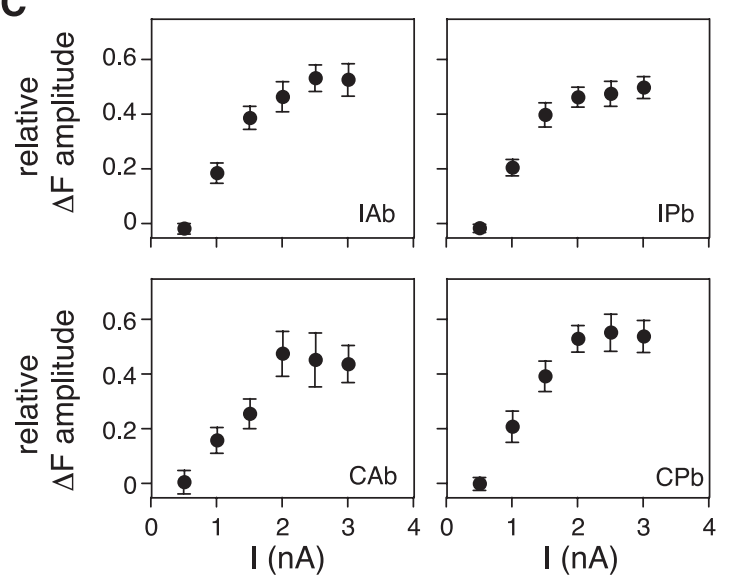

suggesting that the calcium transients depended on the inflow of $\mathrm{Ca}^{2+}$ from the extracellular space.

Synaptic inputs evoke calcium transients in NS neurons. Having shown that depolarization of NS neurons by means of low-threshold-rebound spikes and current pulse injection evoke calcium transients throughout their four main branches, our next goal was to analyze whether depolarizing synaptic responses were able to activate this widespread signaling mechanism. Excitation of the pressure mechanosensory $(\mathrm{P})$ cells evokes complex synaptic responses in NS neurons that are composed of phasic depolarizing potentials superimposed on a tonic hyperpolarization, where the relative weight of the depolarizing and hyperpolarizing components of the synaptic responses varies from preparation to preparation (Marín Burgin and Szczupak 2000).

To study whether synaptic inputs evoke calcium transients, we performed dual intracellular recordings in the imaging setup. One electrode recorded OG-1 filled NS neurons and a second electrode was used to record and stimulate one of the four $\mathrm{P}$ cells present in the ganglion. Figure 8 shows a representative example of the electrophysiological and optical signals displayed by an NS cell in response P-cell stimulation. Figure 8 shows that the barrage of depolarizing synaptic potentials was accompanied by a calcium transient.

As with depolarizing pulses injected in the soma, synaptic responses of increasing amplitude evoked a gradual increase in $\Delta \mathrm{F} / \mathrm{F}$ signals. Figure $9 A$ shows the responses of an NS neuron to 1-s spike trains of increasing frequency in an ipsilateral lateral $\mathrm{P}$ (Pil) cell. The magnitude of the $\Delta \mathrm{F} / \mathrm{F}$ signals depended on the magnitude of the synaptic response. Figure $9 B$ presents a summary of the whole set of stimuli applied in the neuron shown in A where, in addition, we also stimulated a medial contralateral $\mathrm{P}$ cell $(\mathrm{Pcm})$. The results show that the amplitude of $\Delta \mathrm{F} / \mathrm{F}$ was a linear function of the magnitude of the postsynaptic response, irrespective of the identity of the $\mathrm{P}$ cell. Note that in this series the Pil cell was stimulated twice at $15 \mathrm{~Hz}$ but elicited responses of different magnitude in each case that caused correspondingly different $\Delta \mathrm{F} / \mathrm{F}$ signals.

To summarize the results of this series of experiments across different preparations, and given the variability in the amplitude of

Fig. 5. Depolarizing pulses evoked calcium transients throughout the NS branches. $A: \Delta \mathrm{F} / \mathrm{F}$ signals evoked by three 200 -ms electrical pulses of $0.5,1.5$, and $2.5 \mathrm{nA}$ injected in an NS neuron set at $-60 \mathrm{mV}$. Measures were performed in the ipsilateral posterior branch of an NS neuron at a distance of $140 \mu \mathrm{m}$ from the principal neurite. On top, the black box indicates the timing of the depolarizing pulses. Inset: electrophysiological recordings corresponding to the period enclosed in the line box (vertical scale: $20 \mathrm{mV}$; horizontal scale: $0.5 \mathrm{~s}$ ), showing the electrophysiological responses to the depolarizing 200-ms current pulses. Line steps underneath the recordings indicates the timing of the depolarizing pulses. $B$ : relative amplitude of $\Delta \mathrm{F} / \mathrm{F}$ signals evoked in distal regions of interest (ROIs; at a mean distance of $267 \pm 17 \mu \mathrm{m}$ ) as a function of the magnitude measured in proximal ROIs $(120 \pm 14 \mu \mathrm{m})$. Values are expressed relative to the magnitude of the $\Delta \mathrm{F} / \mathrm{F}$ signals evoked by the low-threshold-rebound spike $(-8 \mathrm{nA}, 2 \mathrm{~s})$ at the corresponding sites. Each point corresponds to the mean response elicited in a single branch by the series of current pulses of 0.5 to $3 \mathrm{nA}$, with $V m_{\mathrm{NS}}$ at $-60 \mathrm{mV}(n=20$ branches in 10 ganglia). Line indicates a distal/proximal ratio of 1 . $C$ : mean relative $\Delta \mathrm{F} / \mathrm{F}$ amplitude as a function of the magnitude of the current pulse in the four main branches ( $n=11,11,5$, and 7 for $\mathrm{IAb}, \mathrm{IPb}, \mathrm{CAb}$, and $\mathrm{CPb}$, respectively) measured in NS neurons set at around $-60 \mathrm{mV}$. Different regions of interest in any single branch were averaged and considered as a single data point $(n=$ 16 ganglia). The identity of the branch is indicated at the right bottom corner of each graph. 
A

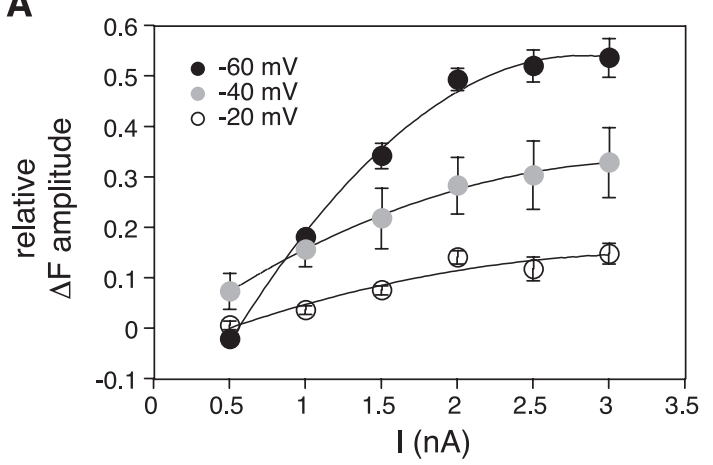

$\mathbf{B i}$

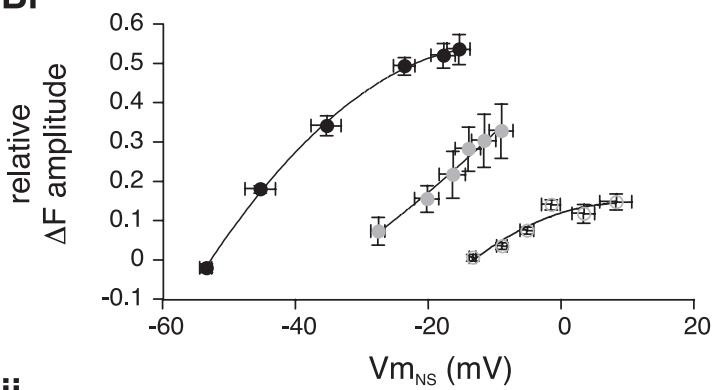

ii

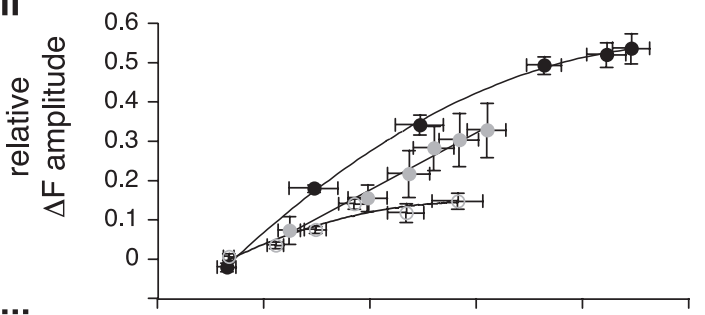

iii

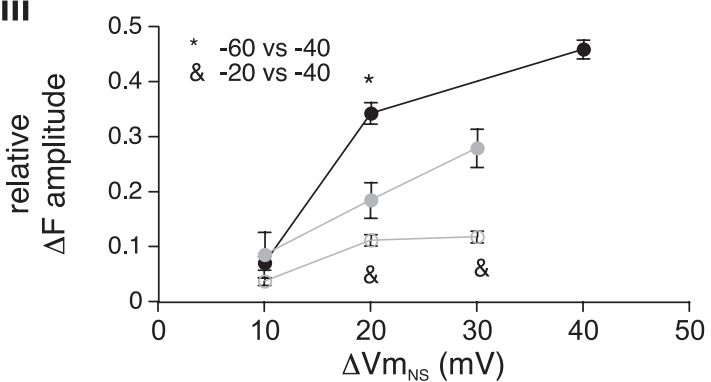

Fig. 6. Graded $V m_{\mathrm{NS}}$ changes evoke graded calcium transients in NS neurons. $A$ : mean relative $\Delta \mathrm{F} / \mathrm{F}$ amplitude as a function of the magnitude of the current pulses for NS neurons set at rest (around $-40 \mathrm{mV}$ ) and at -60 and at $-20 \mathrm{mV}$. Data from the four branches were averaged ( $n=16$ ganglia for -60 and -20 $\mathrm{mV}$ and three ganglia for $-40 \mathrm{mV}$ ); data for $-60 \mathrm{mV}$ correspond to those shown in Fig. 5C. Bi: mean relative amplitude of $\Delta \mathrm{F} / \mathrm{F}$ signals as a function of the average $V m_{\mathrm{NS}}$ values achieved in each condition by the series of electrical pulses (values obtained from Fig. $4 B i$ ). Bii: mean relative amplitude of $\Delta \mathrm{F} / \mathrm{F}$ signals as a function of the average $V m_{\mathrm{NS}}$ change obtained from Fig. 4Bii. Biii: as in $B i i$, but data were binned at $10-\mathrm{mV}$ intervals. In $A$ and $B$, the amplitude is expressed relative to the $\Delta \mathrm{F} / \mathrm{F}$ signal evoked by a low-threshold-rebound spike. For the sake of clarity, the data points in $A$ and $B$ were joined using a second order polynomial function. Symbols on top of the data points indicate $P<0.05$ for responses obtained at $-60 \mathrm{mV}(*)$ and $-20 \mathrm{mV}(\&)$, compared with those obtained at $-40 \mathrm{mV}$, using a two-way ANOVA and planned comparisons.

the synaptic responses found, the synaptically evoked $\Delta \mathrm{F} / \mathrm{F}$ signals were normalized relative to that evoked by a synaptic response of $5 \mathrm{mV}$ (normalized $\Delta \mathrm{F} / \mathrm{F}$ ). The results show that the calcium transients evoked by the synaptic response to $\mathrm{P}$ cells were, to a good approximation, a linear function of the amplitude of the synaptic response (Fig. 9C).

Synaptic inputs evoke widespread calcium transients in NS neurons. The calcium transients evoked by $\mathrm{P}$ cell stimulation could be detected throughout the four main branches. Figure $10 \mathrm{~A}$ displays synaptically evoked $\Delta \mathrm{F} / \mathrm{F}$ signals, detected simultaneously in four ROIs located at the four main branches of an NS neuron. To analyze the distribution of the $\Delta \mathrm{F} / \mathrm{F}$ signals in the neuritic tree of NS neurons we plotted the amplitude of $\Delta \mathrm{F} / \mathrm{F}$ signals evoked by 1-s spike trains in P cells, at $15 \mathrm{~Hz}$, in distal vs. proximal ROIs of the same branch, discriminating ipsi- and contralateral P cells (Fig. 10B). The results show that the signals were relatively smaller in distal than in proximal regions [the average distal to proximal ratio for ipsilateral $(n=27)$ and contralateral P cells $(n=38)$ was $0.84 \pm 0.07$ and $0.76 \pm 0.07$, respectively], but they also indicate that the synaptic inputs propagated throughout the four main branches with relatively small attenuation along each one of them. Figure $10 \mathrm{C}$ documents the mean relative amplitude of the $\Delta \mathrm{F} / \mathrm{F}$ signals measured at proximal ROIs in each of the four branches, indicating that the four branches responded similarly.

Taken together these data indicate that synaptic signals evoke graded calcium transients in NS neurons that are proportional to the magnitude of the electrophysiological response along their four main branches.
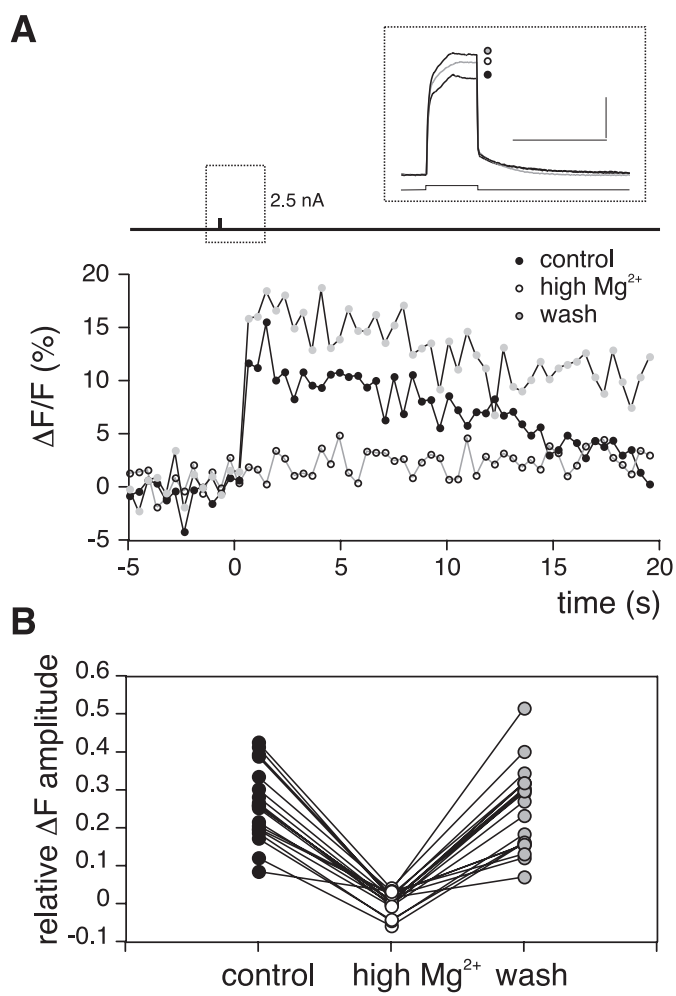

Fig. 7. Calcium transients evoked by depolarizing pulses were blocked in the presence of high $\mathrm{Mg}^{2+}$. A: $\Delta \mathrm{F} / \mathrm{F}$ signals evoked by a $200-\mathrm{ms}$ electrical pulse of $2.5 \mathrm{nA}$, injected in an NS neuron set at $-60 \mathrm{mV}$ in control saline, in high $\mathrm{Mg}^{2+}$, and after a 10-min wash out with normal saline. On top , the black box indicates the timing of the depolarizing pulses. Inset: electrophysiological recordings corresponding to the period enclosed in the line box (vertical scale: $40 \mathrm{mV}$; horizontal scale: $0.4 \mathrm{~s}$ ), showing the responses to the depolarizing 200-ms current pulses. $B$ : amplitude of the $\Delta \mathrm{F} / \mathrm{F}$ signals measured in the three conditions ( $n=19$ neurites in 3 ganglia). Each data point is the mean response to the full series of pulses $(0.5-3 \mathrm{nA})$ and is expressed relative to the $\Delta \mathrm{F} / \mathrm{F}$ signal evoked by a low-threshold-rebound spike. 

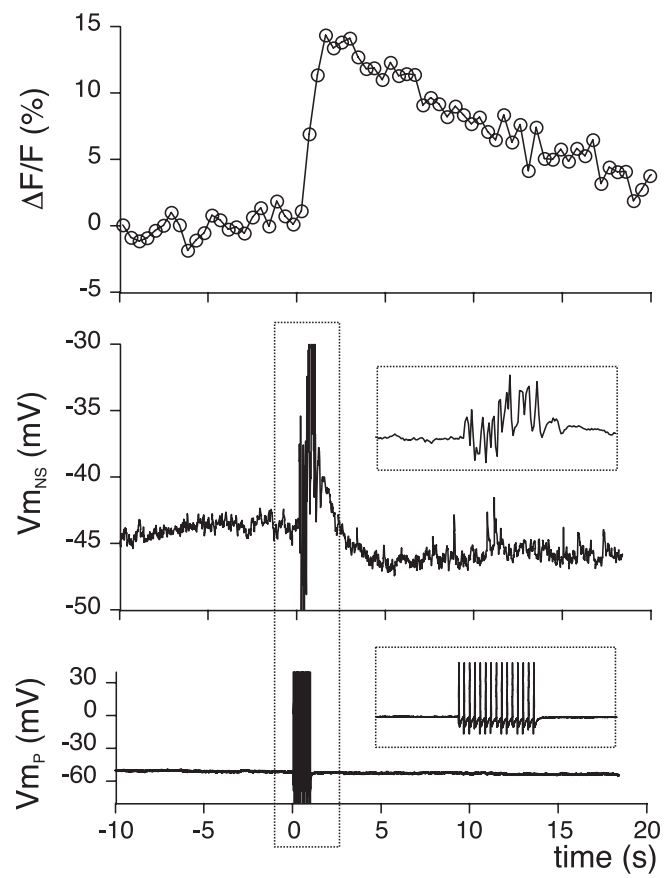

Fig. 8. Synaptic signals evoke calcium transients. $\Delta \mathrm{F} / \mathrm{F}$ signal (top) evoked by the synaptic response of an NS neuron (middle) to a 1-s train of spikes fired by a mechanosensory P cell at $15 \mathrm{~Hz}$ (bottom). To the right of the electrophysiological responses we show an expanded view of the segment enclosed in the broken line box.

\section{DISCUSSION}

Voltage-gated conductances in NS neurons. The results presented here show that the NS neuron is a nonspiking cell that far from being ruled by its passive membrane properties is strongly influenced by voltage-gated conductances that contribute to the amplification and propagation of depolarizing signals through its extensive neuritic tree.

The low-threshold spike is a very robust phenomenon that has been useful for identifying the NS neuron through intracellular recordings, but, as such, this regenerative response has not been observed in the course of elicited or spontaneous synaptic responses. However, through the characterization of this regenerative response, we learned that the NS neurons express a low threshold VACC that is sensitive to high $\mathrm{Mg}^{2+}$ and a voltageactivated $\mathrm{K}^{+}$conductance that is sensitive to TEA (Rela et al. 2009). Here we show that depolarizing current pulses evoked changes in $V m_{\mathrm{NS}}$ that were amplified by a voltage-gated conductance whose characteristics are compatible with those of the VACCs, which underlie the low-threshold spike. Namely, the amplification was potentiated by shifting the membrane potential baseline to values more negative than rest, that caused a deinactivation of the low threshold VACCs. The activation of the NS low-threshold spike is not an all-or-none phenomenon, but its amplitude depends on the magnitude of the stimulus (Rela et al. 2009). Consistently, gradually increasing current pulses produced a graded magnification of the response.

Spatial distribution of VACC. The optical recordings showed that, due to these voltage-activated conductances, NS neurons can operate as an electrically compact structure. The calcium transients elicited by low-threshold-rebound spikes, depolarizing pulses, or synaptic stimulation were recorded throughout the four main branches of the NS neurons, indicating that these neurons are provided with a mechanism to propagate depolarizing signals in an efficient manner.

The sensitivity of the calcium transients to high extracellular $\mathrm{Mg}^{2+}$ (Fig. 7) supports the interpretation that $\mathrm{Ca}^{2+}$ entry from the extracellular space is required to produce them throughout the neuron. Even considering the constraints imposed by the acquisition frequency of the optical recordings the results cannot be explained by $\mathrm{Ca}^{2+}$ diffusion along the neurites

\section{A}
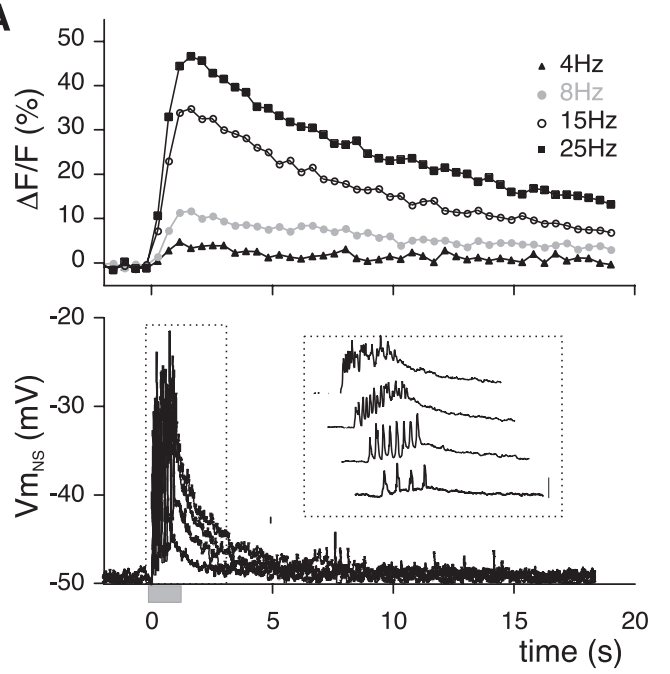

B
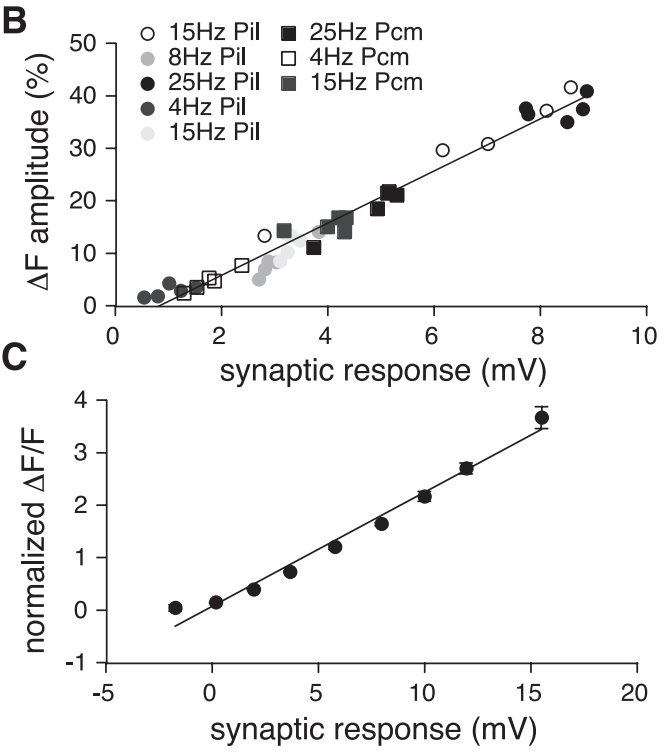

Fig. 9. Increasing synaptic signals evoke gradually increasing calcium transients. A: $\Delta \mathrm{F} / \mathrm{F}$ (top) evoked by the synaptic responses of an NS neuron (bottom panel) to $\mathrm{P}$ cell stimulation. Ipsilateral lateral $\mathrm{P}$ cell was stimulated with 1-s trains of spikes at increasing frequencies $(4,8,15$, and $25 \mathrm{~Hz})$. The gray box underneath the NS recordings shows the timing of the train. Inset: fragment (from -0.5 to $3 \mathrm{~s}$ ) of the $V m$ responses, displaced in $x$ and $y$ (vertical scale: $10 \mathrm{mV}$ ). $B$ : amplitude of $\Delta \mathrm{F} / \mathrm{F}$ signals as a function of the amplitude of the synaptic response in one ROI. Each symbol corresponds to the stimulation of two different $\mathrm{P}$ cells [circles for an ipsilateral lateral (Pil) and squares for a contralateral medial (Pcm)] at the indicated firing frequencies. Results of Pil correspond to the example shown in A. Each data point corresponds to the measurements made in the same region of interest. Line shows a linear fit $(R=0.98)$. $C$ : mean normalized amplitude of $\Delta \mathrm{F} / \mathrm{F}$ signals as a function of the amplitude of the synaptic response $(n=79$ ROIs, 14 synapses, and 9 ganglia). Each measurement was normalized to that obtained (or interpolated) for a synaptically evoked change in $V m_{\mathrm{NS}}$ of 5-mV, in the corresponding ROI. Finally, data were grouped in $2-\mathrm{mV}$ bins. The line shows a linear fit $(R=0.99, P<0.001)$. 


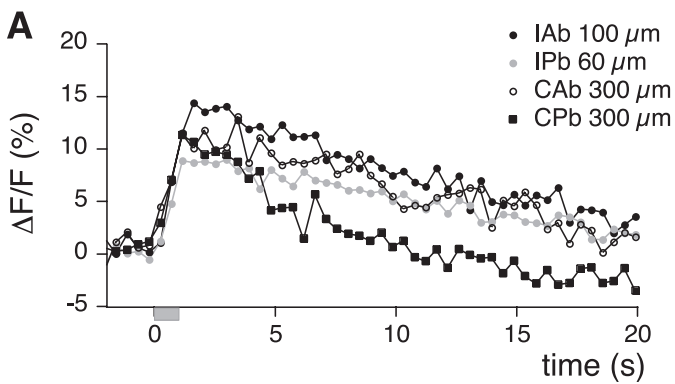

B

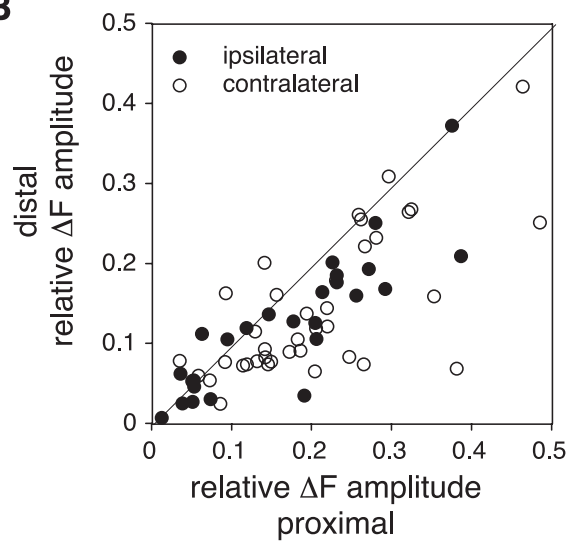

C

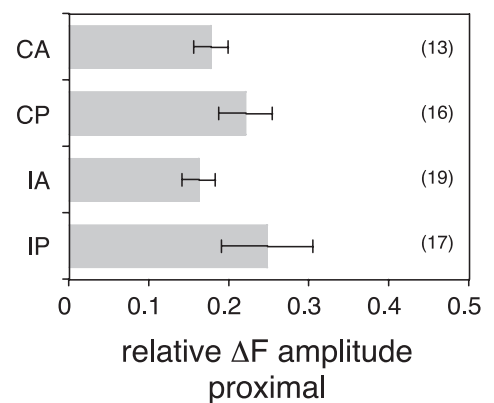

Fig. 10. Synaptic response evoked calcium transients throughout the NS branches. $A: \Delta \mathrm{F} / \mathrm{F}$ signals evoked by stimulation of an ipsilateral lateral $\mathrm{P}$ cell at $15 \mathrm{~Hz}$ at four different sites throughout the NS tree. Gray bar underneath the traces indicates the timing of the spike train in the P cell. $B$ : relative amplitude of $\Delta \mathrm{F} / \mathrm{F}$ signals evoked by P-cell stimulation (1-s train at $15 \mathrm{~Hz}$ ) in distal ROIs (at a mean distance of $205 \pm 8 \mu \mathrm{m}$ for ipsilateral branches and $289 \pm 8 \mu \mathrm{m}$ for contralateral branches) as a function of the amplitude measured in proximal ROIs (at a mean distance of $94 \pm 8 \mu \mathrm{m}$ for ipsilateral branches and $157 \pm 12$ $\mu \mathrm{m}$ for contralateral branches). Values are expressed relative to the amplitude of the $\Delta \mathrm{F} / \mathrm{F}$ signals evoked by a low-threshold-rebound spike $(-8 \mathrm{nA}, 2 \mathrm{~s})$ at the corresponding sites. Each point corresponds to the responses of one branch ( $n=66$ branches in 19 ganglia). Line indicates a distal/proximal ratio of 1 . $C$ : mean relative amplitude of the proximal responses of each branch to stimulation of P cells, whose somata are ipsilateral (ips) and contralateral (cont) to the NS neuron. Number in brackets indicate $n$.

(Augustine and Neher 1992). Thus this result indicates that NS neurons express low threshold VACC throughout its neuritic tree and suggests that this conductance could be responsible for the active propagation of $V m_{\mathrm{NS}}$ changes.

While the calcium transients were most probably due to the activation of low threshold VACCs, the results do not exclude the possibility that the signal also depended on the activation of high-voltage calcium conductances and/or internal stores (i.e., $\mathrm{Ca}^{2+}$-induced $\mathrm{Ca}^{2+}$-release). This question requires further investigation.

The wide distribution of VACCs in neurites does not come as a surprise, such distribution has been reported in several types of neurons (Migliore and Shepherd 2002). The fact that $\mathrm{Na}^{+}$- or $\mathrm{Ca}^{2+}$-dependent spikes can activate calcium transients widely throughout neuritic trees has been shown in other leech neurons, such as the mechanosensory neurons (Ross et al. 1987; Andjelic and Torre 2005), the heart interneurons (Ivanov and Calabrese 2000), and the serotonergic Retzius neurons (Beck et al. 2001); in neurons of the crab stomatogastric ganglion (Graubard and Ross 1989); and in the dendritic trees of mammalian central nervous system neurons, such as cerebellar Purkinje neurons (Lev-ram et al. 1992), cortical pyramidal neurons (Schiller et al. 1995), cortical interneurons (Goldberg et al. 2003), hippocampal CA1 pyramidal neurons (Yuste and Denk 1995), CA1 pyramidal interneurons (Rozsa et al. 2004), and granule cells of the olfactory bulb (Egger et al. 2003).

However, in spite of a widespread VACCs distribution, activation of calcium transients by subthreshold synaptic stimulation can prove to be highly restricted, as shown in the dendritic tree of cortical and hippocampal CA1 pyramidal neurons (Yuste and Denk 1995; Schiller et al. 1997), in cerebellar Purkinje neurons (Eilers et al. 1995), and in granule cells of the olfactory bulb (Egger et al. 2005) or nil as in wind sensitive giant interneuron of crickets (Ogawa et al. 2000). Voltage steps in fly visual interneurons showed widely distributed calcium signals (Haag and Borst 2000), but visual stimulation of these neurons caused restricted calcium signals (Egelhaaf and Borst 1995). In NS neurons, instead, synaptic stimulation activated calcium transients throughout its neuritic tree.

Graded nature of the calcium transients. A remarkable characteristic of the calcium signals evoked in NS neurons by current pulses and synaptic inputs was that, in spite of its wide spatial reach, its amplitude was a graded function of the voltage signal. Fully developed low-threshold-rebound spikes evoked large calcium transients (Fig. 3), but graded electrically or synaptically induced depolarizations evoked graded $\Delta \mathrm{F} / \mathrm{F}$ signals, indicating that the calcium transients were not an all-or-none phenomenon.

Synaptically induced graded calcium transients have been reported in other neurons (Eilers et al. 1995; Helmchen et al. 1999), but in these cases signals were highly restricted in space. NS neurons reveals a case in which graded depolarizing potentials, able to elicit calcium transients, are propagated with high efficiency throughout an extensive neuritic tree, turning it electrically compact for this kind of signals.

Functional implications. For a neuron whose output is a graded function of membrane potential, the effective propagation of graded signals implies that inputs at any site of the neuritic tree can reach distant regions, and influence all its targets, in a way that is proportional to the input magnitude. While this mechanism is highly relevant for nonspiking neurons like the NS, it can also be of importance for spiking neurons that express graded synaptic transmission (Graubard et al. 1983; Arbas and Calabrese 1987; Angstadt and Calabrese 1991). Efficient transmission of graded signals could also be important for the integration of signals in dendritic trees of spiking neurons, where the graded magnitude of synaptic inputs could directly influence the firing frequency at their axon, irrespective of their site of origin.

Given the wide interaction of the NS neuron with the whole population of excitatory motoneurons, the present results indicate that depolarizing changes in $V m_{\mathrm{NS}}$ could affect the whole population of motoneurons simultaneously. Due to the rectifying nature of the electrical coupling between NS and the motoneurons, the profile of the effect on the different motoneurons would 
depend on the transjunctional potential. The propagation of depolarizing signals would selectively uncouple the motoneurons whose membrane potential is more negative than that of NS at any given time. Future work should establish how the calcium transients of NS neurons affect the electrically coupled neurons in the context of motor behaviors, and the optical recordings should prove to be an appropriate experimental tool for this purpose.

\section{ACKNOWLEDGMENTS}

We thank Dr. Alejandro Delorenzi for help at the initial steps of the present work and Dr. Nechama Lasser-Ross, Dr. William N. Ross, and Dr. Lucas Pozzo Miller for invaluable discussion of the results. We also thank Dr. Martín Berón Astrada, Dr. Fernando Marengo, Dr. Violeta Medan, and Dr. Francisco Urbano for in-depth discussion of this manuscript.

\section{GRANTS}

The research was supported by grants from the University of Buenos Aires (X-216) and Foncyt (PICT 2006-1033; to L. Szczupak).

\section{DISCLOSURES}

No conflicts of interest, financial or otherwise, are declared by the author(s).

\section{AUTHOR CONTRIBUTIONS}

Author contributions: S.M.Y. and M.E.V. performed experiments; S.M.Y., M.E.V., and L.S. analyzed data; S.M.Y., L.R., and L.S. interpreted results of experiments; S.M.Y. and L.S. prepared figures; S.M.Y., L.R., and L.S. approved final version of manuscript; L.R. and L.S. edited and revised manuscript; L.S. conception and design of research; L.S. drafted manuscript.

\section{REFERENCES}

Andjelic S, Torre V. Calcium dynamics and compartmentalization in leech neurons. J Neurophysiol 94: 4430-4440, 2005.

Angstadt JD, Calabrese RL. Calcium currents and graded synaptic transmission between heart interneurons of the leech. J Neurosci 11: 746-759, 1991.

Arbas EA, Calabrese RL. Slow oscillations of membrane potential in interneurons that control heartbeat in the medicinal leech. J Neurosci 7: 3953-3960, 1987.

Augustine GJ, Neher E. Neuronal $\mathrm{Ca}^{2+}$ signalling takes the local route. Curr Opin Neurobiol 2: 302-307, 1992.

Baylor DA, Nicholls JG. Chemical and electrical synaptic connexions between cutaneous mechanoreceptor neurones in the central nervous system of the leech. J Physiol 203: 591-609, 1969.

Beck A, Lohr C, Deitmer JW. Calcium transients in subcompartments of the leech retzius neuron as induced by single action potentials. J Neurobiol 48: $1-18,2001$.

Burrows M. Graded synaptic interactions between local premotor interneurons of the locust. J Neurophysiol 42: 1108-1123, 1979.

Egelhaaf M, Borst A. Calcium accumulation in visual interneurons of the fly: stimulus dependence and relationship to membrane potential. J Neurophysiol 73: 2540-2552, 1995.

Egger V, Svoboda K, Mainen ZF. Dendrodendritic synaptic signals in olfactory bulb granule cells: local spine boosts and global low-threshold spike. J Neurosci 25: 3521-3530, 2005.

Egger V, Svoboda K, Mainen ZF. Mechanisms of lateral inhibition in the olfactory bulb: efficiency and modulation of spike-evoked calcium influx into granule cells. J Neurosci 23: 7551-7558, 2003.

Eilers J, Augustine GJ, Konnerth A. Subthreshold synaptic $\mathrm{Ca}^{2+}$ signalling in fine dendrites and spines of cerebellar Purkinje neurons. Nature 373: 70-77, 1995.

Goldberg JH, Yuste R, Tamas G. $\mathrm{Ca}^{2+}$ imaging of mouse neocortical interneurone dendrites: contribution of $\mathrm{Ca}^{2+}$-permeable AMPA and NMDA receptors to subthreshold $\mathrm{Ca}^{2+}$ dynamics. $J$ Physiol 551: 67-78, 2003.

Graubard K, Raper JA, Hartline DK. Graded synaptic transmission between identified spiking neurons. J Neurophysiol 50: 508-521, 1983.

Graubard K, Ross WN. Regional distribution of calcium influx into bursting neurons detected with arsenazo III Proc Natl Acad Sci USA 82: 5565-5569, 1989.
Haag J, Borst A. Spatial distribution and characteristics of voltage-gated calcium signals within visual interneurons. J Neurophysiol 83: 1039-1051, 2000.

Hausser M, Mel B. Dendrites: bug or feature? Curr Opin Neurobiol 13: 372-383, 2003.

Hausser M, Spruston N, Stuart GJ. Diversity and dynamics of dendritic signaling. Science 290: 739-744, 2000.

Helmchen F, Svoboda K, Denk W, Tank DW. In vivo dendritic calcium dynamics in deep-layer cortical pyramidal neurons. Nat Neurosci 2: 989996, 1999.

Husch A, Paehler M, Fusca D, Paeger L, Kloppenburg P. Distinct electrophysiological properties in subtypes of nonspiking olfactory local interneurons correlate with their cell type-specific $\mathrm{Ca}^{2+}$ current profiles. $J$ Neurophysiol 102: 2834-2845, 2009.

Ivanov AI, Calabrese RL. Intracellular $\mathrm{Ca}^{2+}$ dynamics during spontaneous and evoked activity of leech heart interneurons: low-threshold ca currents and graded synaptic transmission. J Neurosci 20: 4930-4943, 2000.

Laurent G. Voltage-dependent nonlinearities in the membrane of locust nonspiking local interneurons, and their significance for synaptic integration. J Neurosci 10: 2268-2280, 1990.

Lev-ram V, Miyakawa H, Lasser-Ross N, Ross EM. Calcium transients in cerebellar Purkinje neurons evoked by intracellular stimulation. $J$ Neurophysiol 68: 1167-1177, 1992.

Magee JC. Dendritic integration of excitatory synaptic input. Nat Rev Neurosci 1: 181-190, 2000.

Marín Burgin A, Szczupak L. Processing of sensory signals by a non-spiking neuron in the leech. J Comp Physiol A 186: 989-997, 2000.

Migliore M, Shepherd GM. Emerging rules for the distributions of active dendritic conductances. Nat Rev Neurosci 3: 362-370, 2002.

Muller KJ, Nicholls JG, Stent GS. Neurobiology of the Leech. Cold Spring Harbor, NY: Cold Spring Harbor Laboratory, 1981.

Neher E, Augustine GJ. Calcium gradients and buffers in bovine chromaffin cells. J Physiol 450: 273-301, 1992.

Ogawa H, Baba Y, Oka K. Spike-dependent calcium influx in dendrites of the cricket giant interneuron. J Neurobiol 44: 45-56, 2000.

Protti DA, Flores-Herr N, von Gersdorff H. Light evokes $\mathrm{Ca}^{2+}$ spikes in the axon terminals of a retinal bipolar cell. Neuron 25: 215-227, 2000.

Rela L, Szczupak L. Coactivation of motoneurons regulated by a network combining electrical and chemical synapses. J Neurosci 23: 682-692, 2003.

Rela L, Szczupak L. In situ characterization of a rectifyng electrical junction. J Neurophysiol 97: 1405-1412, 2007.

Rela L, Yang SM, Szczupak L. Calcium spikes in a leech nonspiking neuron. $J$ Comp Physiol A Neuroethol Sens Neural Behav Physiol 195: 139-150, 2009.

Reyes A. Influence of dendritic conductances on the input-output properties of neurons. Аnпu Rev Neurosci 24: 653-675, 2001.

Rodriguez MJ, Alvarez RJ, Szczupak L. Effect of a nonspiking neuron on motor patterns of the leech. J Neurophysiol 107: 1917-1924, 2012.

Rodriguez MJ, Perez-Etchegoyen CB, Szczupak L. Premotor nonspiking neurons regulate coupling among motoneurons that innervate overlapping muscle fiber population. J Comp Physiol A 195: 1432-1351, 2009.

Ross WN, Arechiga H, Nicholls JG. Optical recording of calcium and voltage transients following impulses in cell bodies and processes of identified leech neurons in culture. J Neurosci 7: 3877-3887, 1987.

Rozsa B, Zelles T, Vizi ES, Lendvai B. Distance-dependent scaling of calcium transients evoked by backpropagating spikes and synaptic activity in dendrites of hippocampal interneurons. J Neurosci 24: 661-670, 2004.

Schiller J, Helmchen F, Sakmann B. Spatial profile of dendritic calcium transients evoked by action potentials in rat neocortical pyramidal neurones. J Physiol 487: 583-600, 1995.

Schiller J, Schiller Y, Stuart G, Sakmann B. Calcium action potentials restricted to distal apical dendrites of rat neocortical pyramidal neurons. $J$ Physiol 505: 605-616, 1997.

Segev I, London M. Untangling dendrites with quantitative models. Science 290: 744-750, 2000.

Thoreson WB, Rabl K, Townes-Anderson E, Heidelberger R. A highly $\mathrm{Ca} 2$-sensitive pool of vesicles contributes to linearity at the rod photoreceptor ribbon synapse. Neuron 42: 2004.

Wadepuhl M. Depression of excitatory motoneurones by a single neurone in the leech central nervous system. J Exp Biol 143: 509-527, 1989.

Yuste R, Denk W. Dendritic spines as basic functional units of neuronal integration. Nature 375: 682-684, 1995.

Zenisek D, Henry D, Studholme K, Yazulla S, Matthews G. Voltagedependent sodium channels are expressed in nonspiking retinal bipolar neurons. J Neurosci 21: 4543-4550, 2001. 